Ringing Out for

Early Literacy

Using the Bell Awards to Support

ECRR at Your Library

\section{Melissa Depper}

Melissa Depper is Storytime Supervisor for the Arapahoe (CO) Libraries, where she works primarily with early childhood programs and services and leads a team of fourteen storytime providers. She co-founded the Bell Awards with ALSC member Carol Edwards and serves on the ALSC/PLA ECRR Oversight Committee.
$\mathrm{O}$ ne of the strengths of the Every Child Ready to Read five practicesread, write, sing, talk, and play-is that they are foundational components of early childhood library programs and services, and provide ready-made opportunities for engaging parents and caregivers in conversation about their children's learning.

The five practices also served as inspiration for the Bell Picture Book Awards for Early Literacy, a project of Colorado Libraries for Early Literacy, an advisory group to the Colorado State Library.

\section{Introducing the Bells}

The Bell Picture Book Awards, launched in 2013, are an annual national recognition of five high-quality picture books that provide excellent support of early literacy development in young children. In particular, the award recognizes and honors those picture books that support and/or model the early literacy practices. One book is recognized each year in each category of Read, Write, Sing, Talk, and Play.

What does it mean, to support or model early literacy practices through books? Consider two titles from the Play category of the Silver Bell Honor Books (twenty-five books that meet the Bell Awards selection criteria, published in the twenty-five years before the awards' first year).

Press Here by Hervé Tullet, with direct invitations to touch the pages, shake the book, and blow on the pictures, creates a situation where it is easy for readers to engage in play-families find themselves pushing the buttons and making discoveries almost whether they mean to or not. That's great support for play: the book itself helps make play happen.

Another Play Silver Bell title, Pete's a Pizza by William Steig, is a solid example of a book that models play. While reading the story together, caregivers and children both get a sneak peek at another family in the middle of an imaginative, vocabulary-rich, open-ended play time.

\section{The Bell Awards as Early Literacy Tools}

The Bell Awards were designed in part to support libraries and early childhood educators in creating and providing early literacy services, through collection development, parent/caregiver education, and staff training.

\section{Collection Development}

In addition to naming the five winning books, the Selection committee releases a five-title shortlist for each of the practice categories prior to the award announcement, which means that the Selection committee identifies twenty-five strong picture books each year suitable for public library 
and early childhood collections_-and, of course, for readers' advisory conversations and displays.

Libraries have also used the Bell Award titles to add to circulating storytime-to-go bags, early literacy activity kits, and professional storytime collections. The Bell books have been listed on reading challenge sheets—read them all for a prize!

\section{Parent and Caregiver Education}

For each winning title, and for all twenty-five Silver Bell books (forty titles so far), the Bell Award Selection committees have written a single-page activity and information sheet. These sheets are free to download from the CLEL website (www .clel.org) and include an annotation indicating connections between the title and early literacy skills and practices as well as three or four activity ideas.

These activity ideas are suitable for storytimes, preschool circle times, or for family time at home. Since each activity idea is listed with a statement connecting it with an early literacy skill or practice, they help adults learn how what they do at home with their children builds critical pre-reading skills.

Libraries are free to print and hand out the sheets during parent workshops, family programs, or caregiver trainings.

Does your library write a blog or a parent newsletter? Feel free to use Bell Award books and a corresponding activity idea from the information sheets as content; just indicate the source!

\section{Staff Training}

For youth services staff new to storytime, the information sheets can also support ongoing early literacy training. Reading how each activity idea connects with both a book and a skill or practice can underline the early literacy concepts and bring them to life.

For seasoned staff looking for fresh storytime material, information from past information sheets can easily be adapted into storytime literacy messages that coordinate with Bell Award titles or other, similar books.

The Bell Awards are a new resource that draw on established research and the Every Child Ready to Read concepts to give libraries yet another way to present early literacy strategies and develop creative ways to help children and families.

The 2017 awards will be announced February 5, 2017. For more information, to suggest a title, or to download the information sheets, visit www.clel.org and select the Bell Awards tab. If you have questions, email clelbellawards@gmail.com.

Thanks to Vicky Hays, Poudre River Public Library District; Stella Fowler, Boulder Public Library; Sarah Johnson, Mamie Doud Eisenhower Public Library, Anna Haase Kreuger, Ramsey County Library; and Mary Kuehner, Arapahoe Libraries, for sharing their strategies for using the Bell Awards.

\section{READINESS MATTERS CONTINUNG EDUCATONN

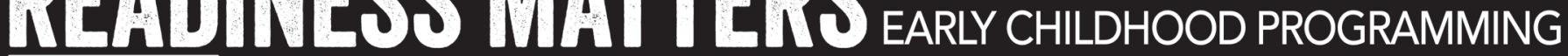

\section{CURREIIT WORKSHOPS:}

- Ready Set Kindergarten: Incorporating school readiness into library programs and story times

- One Shot Story Time: Designing a quality story time

- Take a Gander at Mother Goose: Using Mother Goose and nursery verse with young children

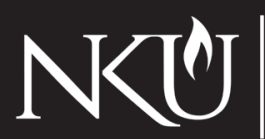

W. FRANK STEELY

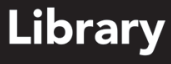

- Techno Toddlers: App happy

- Techno Toddlers: Digital storytime

- Everyday Literature: Books reflecting the everyday experiences of young children

- Exploring World-changing Literature

Registration available at libraryeducation.nku.edu
- Interactive Books for Young Children

- READiness Matters

- Bilingual (Spanish/English) Story Time Basics for Bilingual Presenters

- Bilingual(Spanish/English) Story Time Basics for Non-Bilingual Presenters

- Notable Books and Media for the Very Young

And more workshops coming soont 